\title{
IDENTIDAD INGLESA PREMODERNA Y OTREDAD ROMANA EN CIMBELINO DE SHAKESPEARE: CONSIDERACIONES DESDE EL GÉNERO
}

\author{
Pre-modern English Identity and Roman Otherness in Shakespeare's Cymbeline: \\ SOME Gender-based Considerations \\ IDENTITÉ ANGLAISE PRÉMODERNE ET AUTRETÉ ROMAINE DANS CYMBELINE DE SHAKESPEARE : \\ QUELQUES CONSIDÉRATIONS DU POINT DE VUE DU GENRE
}

\author{
Andrea Bibiana Puchmüller \\ Doctora en Letras, Universidad Nacio- \\ nal de Cuyo, Mendoza, Argentina. \\ Profesora adjunta exclusiva, Cátedra \\ de Literaturas Anglófonas, Departa- \\ mento de Artes, Universidad Nacional \\ de San Luis, Argentina. \\ Av. Ejército de los Andes 950, \\ D5700 BPB, San Luis, Argentina. \\ puchmuller@gmail.com \\ http://orcid. \\ org/0000-0002-5683-2856
}

\begin{abstract}
RESUMEN
El objetivo de este trabajo es caracterizar el drama Cimbelino de Shakespeare con base en ciertos aspectos propios del género histórico romano shakesperiano, a través de los cuales se manifiestan diversas tensiones entre la identidad inglesa premoderna y el ethos romano, tomado como modelo imperialista por la Inglaterra jacobina e isabelina. El análisis de la obra se aborda, por un lado, desde una perspectiva histórico-revisionista acerca de la Inglaterra premoderna, y por otro, desde el andamiaje idiosincrático del drama romano de Shakespeare. Se concluye que Cimbelino despliega una irónica dialéctica entre el doble canon del ethos romano, romanitas y pietas, posicionándolo como contradictorio y perjudicial para la salud del organismo político y social. La Roma de Shakespeare en Cimbelino representa todo lo contrario al modelo romano idealizado por la propaganda imperial isabelina en su proceso de construcción de la poiesis nacional.
\end{abstract}

Palabras clave: ethos romano; identidad inglesa; drama histórico romano; Cimbelino; Shakespeare.

\begin{abstract}
This paper aims at characterizing Shakespeare's Cymbeline relying upon some aspects featured by Shakespearean Roman history genre, as those reveal various tensions between the English premodern identity and the Roman ethos, which was considered an imperialist model by Jacobean and Elizabethan England. This analysis is carried out from a revisionist historical perspective of premodern England, and from the idiosyncratic framework of Shakespearean Roman history plays. It is concluded that Cymbeline displays an ironic dialectics between the double canon of Roman ethos, romanitas and pietas, positioning it as contradictory and detrimental for the social health of the body politics. Shakespeare's Rome in Cymbeline represents the contrary to the idealized model used by Elizabethan imperial propaganda in the process of construction of their national poiesis.
\end{abstract}

Keywords: Roman ethos; English identity; Roman history play; Cymbeline; Skakespeare.

Received: 2018-07-09 / Accepted: 2019-09-04 / Published: 2020-01-28

http://www.doi.org/10.17533/udea.ikala.v25n01a12 


\section{RÉSUMÉ}

L'objectif de ce travail est de caractériser le drame Cymbeline de Shakespeare en analysant certains aspects du genre historique romain du poète anglais, aspects qui révèlent diverses tensions entre l'identité anglaise prémoderne et l'éthos romain pris comme modèle impérialiste par l'Angleterre Jacobéenne et Elisabéthaine. L'analyse de l'oeuvre est abordée d'une part, depuis une perspective historique révisionniste sur l'Angleterre prémoderne et d'autre part du point de vue de l'esprit idiosyncratique du drame romain de Shakespeare. On conclut que Cymbeline déploie une ironie dialectique entre le double canon de l'éthos romain, romanitas et pietas, en le présentant comme contradictoire et nuisible à la santé sociale de l'organisme politique. La Rome de Shakespeare dans Cymbeline s'oppose au modèle romain idéalisé par la propagande impériale élisabéthaine pour construire la poiesis nationale.

Mots clés : éthos romain; identité anglaise; drame historique romain ; Cymbeline; Shakespeare. 


\section{Introducción}

El campo crítico shakesperiano, Cimbelino ([1623]1998) ha presentado problemas de clasificación. A lo largo de los años, se lo ha catalogado como: una comedia (Evans, 1960), la apoteosis de la comedia moral (Frye, 1968, p. 237), un romance (Alexander, 1979; Halio, 1992; Monney, 1992; Waller, 1992; Del Sapio Garbero, 2016), una autoparodia (Bloom, 2001, p. 630), una tragicomedia (Ronan, 1995), una pieza híbrida (Piña, 2007,p. 15), un drama colonial (Heinze, 2016) y un drama histórico romano (Miola, 1983; Kahn, 1987; Lee, 2007). Desde el punto de vista estético, pero que indirectamente involucra el campo de los géneros discursivos, muchos estudiosos han maltratado esta obra por ser demasiado experimental y desplegar una estructura dramática despareja y descentrada (Piña, 2007, p. 9). Tal es el caso del doctor Johnson (1765), quien considera que

La obra tiene muchos sentimientos justos, algún diálogo natural y algunas escenas agradables, pero se logran a expensas de mucha incoherencia. Señalar lo loco de la ficción, lo absurdo de la conducta, la confusión de los hombres, los modales de diferentes tiempos y la imposibilidad de los acontecimientos en todo sistema de vida, sería desperdiciar la crítica en una imbecilidad sin consistencia, en faltas demasiado evidentes para detectarlas, y demasiado groseras para agravarlas. (p. 198)

Si se tiene en cuenta el cambio de paradigma (en términos de Kuhn, 1990) de la época de Johnson a la actual postmodernidad, sumado a nuevas miradas revisionistas del contexto histórico de Cimbelino, es factible constatar que "las incoherencias", "lo absurdo", los "diferentes tiempos" y "la imposibilidad de los acontecimientos" que con tanta intransigencia critica Johnson (1765), son precisamente factores determinantes del drama histórico romano, ${ }^{1}$ y que distantes de ser "una imbecilidad sin consistencia”, crean un todo absolutamente coherente en Cimbelino.

1 Las otras obras shakesperianas que corresponden a este género son Tito Andrónico, Julio César, Coriolano y Antonio y Cleopatra.
En el mismo orden de cosas, los pocos críticos que estudian la obra como un exponente del drama histórico romano lo hacen desde otras perspectivas y tratan la idiosincrasia del género de manera tangencial. Un claro ejemplo es el estudio de Miola (1983) que, aunque sumamente esclarecedor en numerosos aspectos, concluye que Cimbelino reconoce la grandiosidad que fue Roma (p. 207), y que la seriedad de los anteriores esfuerzos romanos de Shakespeare, resultantes del permanente interés en el carácter y la política, conducen aquí a una arrogante despreocupación que tolera las inconsistencias, se abstiene del análisis político y pregona sus propios artificios (Miola, 1983, p. 206).

En oposición a lo supuesto por Miola, en este trabajo se intentará demostrar que la Roma escénica del Cimbelino de Shakespeare dista de ser una Roma gloriosa y es, por el contrario, egoísta, contenciosa, cruel y hostil. Por otro lado, Cimbelino no se abstiene del análisis social o político, ya que la obra explora las tensiones que afloran del choque de dos culturas, la romana y la inglesa, y que se vinculan con la construcción de la identidad inglesa en el momento histórico de su escritura. De igual modo, las 'inconsistencias' que la obra 'tolera' según Miola, son desterradas por ciertas características del género, que funcionan para darle coherencia al mismo, y que develan que Cimbelino no es un drama vacío de análisis y posibilidad de reflexión crítica.

A partir de lo expuesto, este trabajo se propone caracterizar Cimbelino desde ciertos aspectos propios del género $^{2}$ histórico romano shakesperiano mediante los cuales se manifiestan diversas tensiones entre la identidad inglesa premoderna y el ethos romano tomado como modelo imperialista por la Inglaterra jacobina e isabelina. El análisis de la obra se aborda,

2 En este trabajo, el constructo de género discursivo se entiende fundamentalmente como un proceso dialéctico, fluido y dinámico, o paradigmático en términos kuhnianos (Kuhn, 1990); es histórica, cultural y socialmente determinado, es decir, conlleva marcas del proceso y del contexto de producción, y constituye una opción del escritor dentro de un marco de posibles (Todorov, 1976; Bazerman, 1994; Lukács, en De Aguiar e Silva, 2005). 
por un lado, desde una perspectiva histórico-revisionista acerca de la Inglaterra premoderna, y por otro, desde el andamiaje idiosincrático del drama romano de Shakespeare.

\section{La Inglaterra premoderna: formación de su poiesis nacional}

Críticos como Tillyard (1943) y Spenser (1957) han caracterizado la premodernidad inglesa (reinados de Isabel I, 1558-1603, y de Jacobo I, 1603-1625) como un universo político y cosmográfico en el que hay un lugar para cada cosa y cada cosa tiene su lugar; un cosmos minucioso, jerarquizado e idealmente racional. Además, la historiografía tradicionalista ha calificado los reinos de Isabel y Jacobo como etapas de gran esplendor cultural, social y político (Halliday, 1985). Sin embargo, una nueva generación de historiadores y críticos literarios pertenecientes a nuevas tradiciones historicistas han cuestionado esa visión monológica del Renacimiento inglés. Greenblat (1988), Pieters (2001), Asquith (2005), entre otros, destacan que es una concepción que no da lugar al conflicto y fracasa en ver que toda cosmovisión histórica contiene un número de contradicciones fundamentales que inevitablemente la convierten en un territorio de apremios políticos e ideológicos. Además, señalan que la postura histórico-tradicionalista restringe su discusión de la cosmovisión colectiva del período a las concepciones de una cierta elite: "El núcleo erudito que dictaminaba las creencias vigentes de la época isabelina" (Tillyard, 1943, p. 29). Esta discusión por lo tanto excluye otras voces que pudieron dar lugar al disenso y a la diferencia.

Los isabelinos de la Inglaterra premoderna sufren un profundo proceso de autodefinición y de construcción de su idiosincrasia, en el cual los valores impuestos por el reinado isabelino y su iglesia son triangulados con los valores de otros sistemas culturales, sociales, filosóficos y políticos —como el Renacimiento, el humanismo, el neoplatonismo, el hermetismo, etc. - conjuntamente con el legado innegable del pensamiento medieval, que les permiten elaborar y entender su identidad nacional en relación con ellos mismos y con el resto de Europa.
El resultado de este proceso de construcción de identidad es un continuo devenir dialéctico, un proceso que Pieters (2001, p. 42) describe como una formación activa (autopoiesis) y una pasiva, un ser formado.

La idiosincrasia de la Inglaterra premoderna está sin duda condicionada por la preocupación isabelina por su ascendencia imperial, que encuentra en el antiguo imperio romano un modelo de alteridad para consolidar su autorrepresentación y su ethos político y social. La historia romana no implica simplemente un pasado para los isabelinos; es el pasado (Hunter, en Lee, 2007, p. 406). El mito de la conexión británico-romana, formulada en el romance medieval de Arturo, es deliberadamente promocionado y divulgado por la monarquía de los Tudor, especialmente después de la asunción de Enrique VIII. En la apropiación de la creencia de que Gran Bretaña habría sido fundada por el legendario Bruto, los ingleses llegan a definirse a sí mismos como legítimos descendientes del imperio romano (Lee, 2007, p. 406). En consecuencia, la antigua Roma provee el modelo perfecto para encauzar los sentimientos nacionalistas e imperialistas de la Inglaterra isabelina; representa el "Otro", un mundo temporalmente remoto imbuido también de los principios de discordia concors, civilizado y brutal, secular y pagano, poderoso y trivial. En este sentido, Ronan (1995, p. 12) acentúa los inescapables contrastes entre el orden y el desorden romano, entre la dedicación romana a las artes —arquitectónicas, literarias, políticas, militares- y el enredo romano con la barbarie y los poderes inhumanos. La racionalidad encierra, nutre, y perpetúa lo demoníaco, lo salvaje y lo bestial en la vida romana; y probablemente lo contrario también sea verdadero (Ronan, 1995, p. 12).

Durante el Renacimiento europeo y la Inglaterra isabelina, la antigua Roma $^{3}$ es ampliamente exaltada por sus valores, normas e instituciones y se convierte en el modelo supremo de la civilización occidental. La Inglaterra premoderna toda está imbuida de la

3 De aquí en adelante el término "Roma” será usado con el sentido de "Roma antigua" y no como la ciudad contemporánea al Renacimiento. 
potestas de Roma que el Renacimiento no duda en reconocer: paredes, fortificaciones, construcciones, monedas, estatuas, ciudades, etc. Además, se rescatan otras reliquias como tradiciones orales y escritos literarios, y la filosofía de Roma, su ley y sus disciplinas militares establecen los estándares de prestigio y excelencia. La historia de Roma se transforma en un mito, una forma de religión secular, inextricablemente conectada a los problemas históricos, filosóficos y humanos de cambio, crecimiento, evolución, revolución, decadencia, corrupción y muerte (Bondanella, 1987), problemas bastante similares a los que preocupan a la visión orgánica renacentista. Roma se presenta como $e l$ mundo y los romanos simbolizan lo mejor que el hombre puede llegar a ser, el hombre en su grado superlativo, el gobernante, el asesino, el estoico, el constructor, el forjador de palabras (Ronan, 1995, pp. 41-43).

Sin embargo, la visión de Roma como forjadora de una historia de esfuerzo artístico y humano sin paralelo es sin duda "una" de las facetas que la Inglaterra premoderna favorece en la construcción histórica del pasado. La historia de Roma es también una historia de crueldad, ambición y degradación moral. Fundada sobre el fratricidio, la ciudad ha sobrevivido de siglo en siglo saqueando, robando, conquistando, ocupando (Hibbert, 2005).

En el Renacimiento inglés también surgen otras voces, marginales, atenuadas y contrarias al estereotipo premoderno de Roma, que presentan a los romanos como "ladronzuelos en los asuntos extranjeros", "presas de sus [propios] tiranos", causantes de "discordia y disensión civil", ambiciosos que se complotaban "en oscuros conventículos en contra de sus superiores” (Spencer, 1957, en Ronan, 1995, p. 45).

El teatro isabelino, como escenario discursivo de la época, también se convierte en un espacio para representar a Roma frente a una audiencia sumamente heterogénea. El teatro es un campo de batalla en el que una gran variedad de discursos opuestos se encuentran y negocian el uno con el otro; es un campo discursivo que abarcaba desde la erudición humanística hasta la historiografía (Kahn,
1987, pp. 8-9). Conscientes de la tensión entre Roma como construcción ideal, mitológica y utilitaria, y la Inglaterra renacentista, real y en formación de su idiosincrasia nacional, los dramaturgos se apropian de este dimorfismo y encuentran materiales para sus obras en cada fuente posible, constantemente experimentando y cruzando los límites genéricos (Lee, 2007, p. 404). Miola (1983, pp. 8-10) señala que detrás de este impulso de representar a Roma sobre el escenario, se esconde en realidad la necesidad utilitaria de establecer paralelos instructivos entre la historia antigua y la política isabelina. La necesidad de la Inglaterra premoderna no es, por lo tanto, conocer fiel y meticulosamente el pasado romano, sino interpretarlo como herramienta de alteridad a la luz de su contexto contemporáneo. El interés de Inglaterra de definirse a sí misma como una nación y como un imperio, y de establecer un cierto orden y seguridad social son algunas de las razones por las que los isabelinos buscan una cultura pasada con la cual identificarse. Inglaterra encuentra en Roma un espejo en el que la isla puede mirar su propia imagen, simultáneamente civilizada y bárbara (Steible, 2004, p. 17).

\section{Andamiaje idiosincrático del género histórico romano shakesperiano}

Hay rasgos distintivos que caracterizan el drama histórico romano de Shakespeare y lo diferencian de otros géneros del mismo dramaturgo. En primer lugar, el género romano shakesperiano alberga un cronotopo único y distintivo: Roma y su color local. Este tipo de drama histórico comienza siempre signado por el caos, la división y la inevitabilidad de la guerra. El argumento es dominado por la crudelitas romana y el elemento grotesco, irónico y satírico. En relación con las dramatis personae, estas son moldeadas por virtudes romanas: pietas y romanitas, y el destino del héroe es signado por seis fases procesuales: división, autodivisión, traición, autotraición, autoconquista y autodestrucción.

La visión de Roma que Shakespeare fabrica en sus obras se refleja en la configuración de un cronotopo propio y único para este género: Roma y su color local (su arquitectura, sus costumbres, su religión, 
su retórica, etc.), y un tiempo histórico particular que varía en cada obra. Pero también la construcción de los cronotopos en el género se realiza desde la preocupación por los temas de la continuidad, la mutabilidad, la espiralidad y la circularidad histórica en el tiempo, así como por la posibilidad de la muerte y la resurrección cultural (Ronan, 1995, p.7). Shakespeare construye a Roma como un potente símbolo de aspiración y control sobre la naturaleza y sobre el tiempo y como un ícono de la conquista histórico-temporal (Paster, en Ronan, 1995, p. 37).

El primer síntoma del género histórico romano es el de las grandes divisiones que ponen en evidencia la enfermedad del cuerpo cívico. Desde la escena inicial de cada una de las obras romanas, el organismo político-social aparece ya corrupto y enfermo, lo que denota que Shakespeare no se propondría caracterizar "cómo" empieza la enfermedad que atenta contra el organismo, sino qué sucede cuando la comunidad toda está enferma. Las vehementes divisiones conducen a la inevitabilidad de la guerra, que se traduce siempre en un conflicto bélico entre los miembros de una comunidad y en la inminente destrucción de la paz cívico-social. Este tema se presenta en cada una de las obras romanas mediante un proceso ascendente de inclusión que complejiza el género: la familia en Tito Andrónico, la ciudad en Julio César, el imperio en Antonio y Cleopatra, la Res publica y el enemigo en Coriolano, hasta llegar a la Bretaña romanizada en Cimbelino, que involucra a los distintos estamentos sociales, al estado y a Roma como el Otro.

La crudelitas romana (sevicia) también se constituye en un instrumento de ataque al cuerpo cívico. El discurso de la crítica al respecto se ha centrado en hacer énfasis en el elemento sangriento en Tito Andrónico, calificando a la obra como demasiado cruenta y sensacionalista, y al mismo tiempo en minimizar la crudelitas en el resto del corpus, con el objetivo de responder a algo más limpio, más literario y más decoroso que las verdaderas obras sangrientas como se verían en el escenario. Las instancias de violencia, de crueldad y de desmembramiento adquieren importancia en este género, ya que contribuyen a demarcar la naturaleza predatoria de los romanos de Shakespeare y a subrayar de manera más enfática el contraste entre ethos y praxis romana, los cuales se develan como instancias análogas al desmembramiento del organismo social (Ronan, 1995). La diferencia radica en que los casos de violencia son puramente miméticos en Tito Andrónico, mientras que en el resto de las obras se entremezclan en la mimesis y en la diégesis. Hay muchas instancias que Shakespeare decide no representar, pero que al ser verbalizadas contribuyen igualmente a la configuración de la crudelitas romana, a la destrucción de la unidad social y a la representación de Roma como una jungla de tigres.

El elemento grotesco, satírico e irónico es también un aspecto idiosincrático de este género (Ronan, 1995 , pp. 4-5). La antigüedad clásica, generalmente estereotipada y simplificada por el mundo isabelino y renacentista como decorosa, seria y honorable, tiene para Shakespeare una connotación grotescamente cómica. Shakespeare imbuye sus obras romanas de una visión dolorosamente burlesca, carnavalescamente dolorosa y patéticamente absurda, e instala sobre el escenario momentos que descuellan en ironía, exageran lo grotesco y pasan repentinamente de lo sublime a lo prosaico y ridículo.

El drama romano dramatiza las consecuencias de las fallas en la comunicación y propugna por la importancia del diálogo como fuerza social cohesiva para el bienestar del organismo. Son, por lo tanto, las relaciones dialógicas las que este género preconiza por sobre el monologismo. El soliloquio, tan importante en la tragedia como recurso que permite acceder a la conciencia y la psiquis del héroe, desaparece o es prácticamente inexistente en el drama histórico romano. Este género casi no hace uso de soliloquios, apartes o diálogos personales en los momentos cruciales en que la lucha interna es más intensa. El yo esencial del protagonista aparece subyugado al yo social de la comunidad de la cual es parte constitutiva, y, por lo tanto, la comunicación interpersonal pasa a ser una función más importante que la introspección. El soliloquio es aquí reemplazado por el diagnóstico, la evaluación y la opinión, entendidos como el análisis de la 
naturaleza de una situación o condición, pero siempre desde intereses personales (Puchmüller, 2007). Por lo tanto, la diagnosis sirve justamente como instrumento dramático para explorar la visión de cada uno de los personajes, visión que se caracteriza por ser parcializada y limitada por el prejuicio, la ignorancia, el oportunismo o la individualización.

Por otro lado, la identidad de los personajes del drama histórico romano shakesperiano se construye a partir de aquellos valores que inspiraron al antiguo estado romano, en particular, aquellos que definían la esencia del ser romano: romanitas y pietas (Reale y Antiseri, 1999). Romanitas implica el ideal romano del ciudadano trabajador, frugal, hombre práctico, extremadamente valiente y capaz de arriesgar su propia vida en nombre de Roma (Thomas, 1991, p. 13). De acuerdo a este ideal, la personalidad del romano debe conjugar una serie de virtudes, tales como honestidad, valor, rectitud, entereza, fortaleza, constancia y honor (Ingledew, 1971, p. xiii). Pietas se refiere al código de conducta del romano para mantener la unidad y la salud del estado como un todo orgánico (Lewis y Short, 1958). Implica deber, devoción y, simultáneamente, sugiere: amor y honor hacia la familia, devoción para con los amigos y el entorno social, devoción y servicio al Estado, y amor y respeto por los dioses (Thomas, 1991, p. 13).

Tales ideales romanos se conjugan en este género sobre todo en la figura del héroe trágico. La tragedia en el género romano shakesperiano se mueve de un drama externo (el organismo social) a un drama interno (el héroe), desde el cuerpo político de Roma hacia el cuerpo político de Tito Andrónico, Bruto, Coriolano, Antonio, Cleopatra y Cimbelino. En este género hay un movimiento hacia una internalización. El destino del protagonista inmerso en el organismo social está siempre delineado por las siguientes fases: división, autodivisión, traición, autotraición, autoconquista y autodestrucción (Puchmüller, 2007). A la división de la sociedad que se manifiesta desde el principio en el drama romano le sigue siempre la autodivisión del héroe.
El héroe se desgarra por la falta de conocimiento de sí mismo y por la tensión entre su vida pública y privada. Su caracterización no se desarrolla en torno al canon occidental y cristiano, en el que la dualidad del individuo es de sus vicios y virtudes.

En la Roma de Shakespeare, la dualidad del héroe aparece en relación con el canon de la cultura romana: afectuosa bondad por un lado (pietas) y destreza bélica y valor por el otro (romanitas). De acuerdo a este canon, un individuo es honorable cuando puede aliar ambos atributos. Por esta razón, la preocupación por el honor surge como un tema específico de este género y no de otros. El conflicto del protagonista reside en no saber cómo reconciliar ambas virtudes, que se mantienen separadas hasta el final. La traición emerge luego de la fragmentación del héroe, quien al ser engañado por algún individuo o grupo de su comunidad se traiciona a sí mismo y distorsiona su propia naturaleza. Más adelante, cuando se percata de su error y del daño que ha causado a su comunidad, el héroe atraviesa una fase de autoconquista, aunque este movimiento se logra mediante su autodestrucción. Esta faceta del destino del héroe culmina con su propia muerte. El suicidio en este género se lleva a cabo como mecanismo de restablecimiento de la salud del organismo social. Los individuos se extirpan del cuerpo cívico como un acto de misericordia. Sin embargo, este acto de piedad llega demasiado tarde y es suicida.

\section{Cimbelino}

En Cimbelino, el último drama romano de Shakespeare, el dramaturgo da un giro abisal a su perspectiva cronotópica. De la familia en Tito Andrónico, la ciudad en Julio César, el imperio en Antonio y Cleopatra, la res publica en Coriolano, se mueve a la Bretaña romanizada en Cimbelino. Roma se transforma en el Otro, son los britanos quienes miran ahora a los romanos y también se miran a sí mismos. Sin embargo, la Bretaña romanizada se parece en demasía a la antigua Roma del canon shakesperiano: el cuerpo cívico es castigado por el caos, los individuos se mueven por motivos egoístas, la percepción de los individuos está signada por el diagnóstico, la 
guerra se torna inevitable, y al final deviene la síntesis, que es irónica y cuestionable. Las instancias de violencia y de descuartizamiento permanecen, la red de relaciones sociales domina el escenario y los valores romanos de pietas y romanitas siguen siendo una preocupación para el ethos de los britones. Asimismo, la visión cíclica del tiempo, con el objetivo de dramatizar la conquista del mismo, también se materializa en Cimbelino.

Sin embargo, hay un elemento de las obras romanas shakesperianas anteriores que se maximiza vehementemente en este drama: la sátira. Cimbelino| es una secuela natural de los dramas romanos, pero al mismo tiempo es una visión satírica de los mismos. Bloom (2001) considera a Cimbelino como una autoparodia de la carrera dramática de Shakespeare, e identifica correspondencias irónicas con otras obras tales como Macbeth, Romeo y Julieta, Otelo, El rey Lear, entre otras, aunque sorprendentemente no reconoce ningún eco con los dramas romanos.

Por su parte, Miola (1983) descubre numerosas resonancias de Tito Andrónico, Julio César, Antonio y Cleopatra y Coriolano en Cimbelino, pero no las interpreta como ironías. Partimos de la hipótesis, entonces, de que Cimbelino repite las características del resto del corpus de manera satírica, construyendo una Bretaña romanizada que despliega el mismo ethos que sus colonizadores, creando así una perspectiva de rechazo hacia sus valores implícitos. En Cimbelino, Shakespeare ironiza la grandiosidad de Roma, reconociendo su triunfo en el tiempo y en la historia, no como un modelo de imitación sociocultural, sino como un modelo digno de crítica.

Cimbelino transcurre durante los gobiernos del emperador Augusto César en Roma y del rey Cimbelino en Bretaña, en el siglo I de la era cristiana. La mayor parte de la acción se concentra en Bretaña, pero "la presencia de Roma, literal y espiritual, es invasiva" (Bergeron, 1980, p. 32). Los cronotopos de la obra se definen mediante la intertextualidad, y su función es enfatizar la mutabilidad de la historia en el tiempo. Mediante la unión del argumento de Cimbelino con otros cronotopos romanos, la obra crea la ilusión de retorno histórico en el que subyace el ethos de Roma como potencia colonizadora. En un ensayo sumamente esclarecedor, Bergeron (1980) establece la historicidad romana de Cimbelino y examina las analogías existentes entre la vida del emperador Augusto y el argumento de la obra shakesperiana, basándose en las fuentes que inspiraron al dramaturgo para escribir Cimbelino.

La caracterización de muchos personajes revela una posible deuda de la historia romana con fuentes históricas; Shakespeare probablemente intentó que imagináramos que Augusto es un análogo de Cimbelino (Bergeron, 1980, p. 36). Al igual que el rey britón, Augusto tiene una hija (Julia) que lo ha decepcionado por su libertino comportamiento libertino, lo que lo lleva a exiliarla por veinte años. El nieto de Augusto se llama Póstumo y es exiliado a una isla para entrenarse en las artes de la guerra. La esposa de Augusto, Livia, es una reina malvada y manipuladora. Divorciada de su primer marido, se casa con Augusto y lo obliga a adoptar a su hijo Tiberio, con la intención de convertirlo en heredero del trono imperial. Además, las crónicas históricas están repletas de referencias al uso habilidoso de Livia con ciertas drogas para causar la muerte a sus supuestos enemigos. Ciertamente, los ecos intertextuales son asombrosos. La historia de Roma y de su emperador Augusto César se repiten en el argumento de Cimbelino, esta vez en Bretaña.

Otra instancia que no es señalada por Bergeron (1980) y que contribuye al mismo efecto, es la mención de Julio César por Cayo Lucio, cuando le recuerda a Coriolano el origen del tributo que deben pagar a Roma:

\footnotetext{
Cuando Julio César — cuyos recuerdos todavía

Viven en los ojos de los hombres y siempre serán tema

Para los oídos y las lenguas- estuvo en Britania

Y la conquistó, Casibelan tu tío,

Famoso por las alabanzas de César tanto como

Por sus hazañas, que las merecían, para él

Y sus sucesores concedió a Roma un tributo (CI, III, i, 3-9)
}

El cronotopo histórico de Julio César, tal como lo presenta Lucio, impone una imagen del poderío de 
Roma como conquistadora de Bretaña, y simultáneamente una imagen de la ubicuidad de Roma como conquistadora del tiempo; César ha persistido y persistirá en la historia. La reina, esposa de Cimbelino, intenta minimizar la estirpe de César: "Una especie de conquista/ hizo César aquí, pero no fue donde se jactó/ diciendo "Vine, vi y vencí" (CI, III, i, 22-24). Sin embargo, al mencionar la célebre frase de su enemigo, la escena se transporta al cronotopo de la batalla de Zela (Fletcher, 1968, p. 92) y revive la celeridad y la destreza militar con la que César obtuvo la victoria. La ubicuidad y el poderío imperial de Roma es asimismo verbalizado por Cimbelino: "La ambición de César/ que se hinchó tanto que casi extendió/ los costados del mundo, contra toda ley,/ nos puso un yugo" (CI, III, i, 49-52).

Asimismo, el exilio de Póstumo, de la Bretaña del siglo I a la Italia renacentista, condenado por la crítica como inconsistente, es un ejemplo más del poderío romano en el tiempo, que por medio del cambio de cronotopo adquiere la connotación de ahistoricidad, pues permanece invariable a lo largo del tiempo. El cronotopo britano caracterizado como netamente romano es evidencia del "retorno histórico" (Ronan, 1995, p. 32) de Roma. Y al transportar la unidad espacio-temporal a la Italia del Renacimiento, el "retorno" se intensifica más notoriamente. La Italia del siglo XIV es la cuna del renovado interés por la cultura clásica griega y romana. Por medio de este cronotopo, la obra no hace más que enfatizar la idea de la circularidad, el triunfo romano sobre la temporalidad y la proyección de su sombra incluso en el período moderno (Ronan, 1995, p. 32). Así, el cronotopo que Shakespeare construye en Cimbelino se destaca por su complejidad: es una fusión de la Bretaña romanizada, la Roma augusta, la Italia renacentista, ecos del pasado romano y elementos atemporales. Esta complejidad hace que "El flujo espiralado y ondulado de la continuidad histórica romana se haga compatible con el sentido de la vida de Inglaterra” (Ronan, 1995, p. 33), de una Inglaterra que demuestra estar todavía en el borde del imperio romano.

Por otra parte, el ethos de los britones de Cimbelino se asemeja al de los romanos de Tito Andrónico, Julio
César, Antonio y Cleopatra y Coriolano. El código de conducta britón permanece delimitado por los mismos constructos: honor, fama, masculinidad y belicosidad, heredados de sus conquistadores. El padre de Póstumo “... ganó su prestigio guerrero/ luchando contra los romanos con Casibelan" (I, i), y sus hijos "... a lo largo de las guerras sucesivas/ murieron con las espadas en mano” (I, i). Asimismo, Cimbelino reconoce su formación militar bajo la tutela de Augusto y acentúa la defensa del honor que él mismo le transmitió: "Tu César me hizo caballero, pasé en gran medida/ mi juventud bajo él; de él recogí mi honor/ que, si quiere arrebatarme ahora/ me corresponde defender a ultranza" (III, i). La virtus de los antepasados britanos se corresponde con el valor romano, pero también con la superbia: “... el famoso Casibelan, que estuvo una vez a punto/ —oh variable fortuna- de dominar la espada de César/ hizo brillar fuegos de festejo en la ciudad de Lud/ y los britanos se hincharon de valor" (III, i).

Roma deviene en el Otro, superior y émulo a la vez, que presenta un modelo para la propia configuración del ethos de los britones. En Cimbelino, la identidad nacional británica se forma por la interacción de los invasores romanos con la tierra nativa (Mikalachki, en Kahn, 1987, p. 163). Sin embargo, la instancia más importante de interacción en la obra adquiere características satíricas. El enfrentamiento bélico entre la armada romana y el pueblo britón se convierte en una sátira de las espectaculares batallas de las obras anteriores. El despliegue de fuerzas romanas es magnífico:

\footnotetext{
Capitán: ... las legiones acantonadas en Galia

Según vuestras órdenes han cruzado el mar.

Os aguardan con naves aquí en el puerto de Milford.

Están esperando órdenes. (CI, IV, ii)

Lucio: ¿Qué sabemos de Roma?

Capitán: El senado ha movilizado a los habitantes

Y caballeros de Italia, espíritus bien dispuestos

Que prometen noble servicio (CI, IV, ii, 333-340)
}

Y sin embargo, en una grandiosa muestra de valor, los romanos son derrotados por "Dos niños, un paso, y un viejo en la segunda infancia" ( $v$, iii) de Bretaña. La batalla, por medio de un relato absurdo, adquiere la connotación de un juego de niños con 
tintes de leyendas hercúleas. Resulta cómico imaginarse a las arriesgadas legiones romanas enfrentarse a un anciano y dos débiles jovencitos:

... un viejo soldado... que merecía una fama

tan larga como la vida que atestigua su blanca barba.

(v, iii)

... dos jovencitos —muchachos más aptos para dedicarse

... a juegos de niños que para cometer matanza semejante

con caras tan lindas como las de damas. (v, iii)

Al mismo tiempo, el relato enfatiza con una exageración cómica el valor del trío britón, digno de una leyenda heroica: "Estos tres, que parecían tres mil por sus muchas acciones” (v, iii) “... empezaron a mirar por el camino donde venían/ y a hacer gestos de leones hacia las picas de los cazadores./ Entonces súbitamente el perseguidor se detuvo, se retiró" (v, iii). Irónicamente, el ejército de Augusto César es derrotado en un paso estrecho: "flamearon gallinas/ donde antaño ondearon águilas" ( $\mathrm{v}$, iii). De esta manera, el águila, símbolo del valor y el orgullo romano, se suplanta grotescamente por el de la gallina. Con respecto al simbolismo del águila, Ronan (1995) destaca que:

La tendencia a visualizar a los romanos nobles como águilas no puede evitar ser acentuada por el uso de ese pájaro como tótem — símbolo apto de la envidia, la crueldad, el dominio y el orgullo así como también de otras cualidades más estoicas y regias [...] Ninguna imagen del orgullo romano es mejor que la del águila porque combina el lado condenable de Roma, salvaje y tiránico, con una vislumbre de sus aspectos más admirables. Debido a que esta ave vive del destrozo de presas, se convierte en... un modelo dudoso para los gobernantes y sus gobiernos. Debido a que se eleva por sobre el resto de la vida terrestre, el águila connota aspiraciones majestuosas y blasfemas. (pp. 111-112)

\section{En Tito Andrónico, Julio César, Antonio y Cleopatra} y Coriolano Roma se perfila como un animal predatorio, ícono de todos los valores representados por el águila. En Cimbelino, la sátira destruye este simbolismo, degradando a Roma al nivel de un animal gallináceo, perteneciente al grupo de aves que no vuelan y de connotación cobarde. Por lo tanto, Cimbelino se mofa de la derrota de los romanos por los britones al convertirla en un episodio burlesco y al mismo tiempo al despojar a los romanos de su ethos ancestral. Irónicamente, la profecía del adivino romano sobre el fin de la guerra colapsa:

$$
\begin{aligned}
& \text { Vi al pájaro de Júpiter, el águila romana, volando } \\
& \text { Desde el húmedo sur hacia esta parte del oeste, } \\
& \text { Donde se desvaneció en los rayos del sol; eso indica, } \\
& \text { Salvo que mis pecados hayan afectado mi adivinación, } \\
& \text { Éxito para el ejército romano (v, ii, 348-352) }
\end{aligned}
$$

Enfatizando la derrota romana, el simbolismo del águila es anglificado en la obra y concedido a Póstumo: "Imogen: [...] un águila elegí/ salvándome de un cuervo" (I, i). En resumidas cuentas, Roma deviene una miniatura caricaturesca frente al ataque britón.

La exploración orgánica de la sociedad se mantiene intacta en Cimbelino ya que, en términos de Miola (1983, p. 24) la obra acentúa la necesidad esencial del mantenimiento y la restauración del orden, la estabilidad y la vida político-social civilizada en una serie de círculos concéntricos que se expanden ascendentes para incluir la familia, el hogar, la ciudad, la nación y el mundo. La multiplicidad de las relaciones propia del género histórico romano se dramatiza en Cimbelino mediante la construcción de tres argumentos paralelos: la separación y la reunión de marido y mujer, y de padre e hijos, y la defensa de Bretaña contra la invasión Romana.

La red social que se teje en la obra enfatiza la eficiencia o la incompetencia de cómo cada individuo satisface las necesidades de sus vínculos, ya sean familiares, de amistad, de camaradería o del estado (pietas). Los individuos de Cimbelino, britanos romanizados, presentan los mismos conflictos que los romanos en relación con la pietas. La intrincada red social hace posible que esos conflictos afloren en conexión con las características de los individuos para asegurar o malograr la estabilidad de la unidad social. Al igual que en el resto de los dramas romanos, al comienzo de la obra el organismo aparece convulsionado, en este caso por la impietas de los britanos hacia la institución de la familia. Cimbelino, como Tito Andrónico, sacrifica los valores filiales hacia 
su familia a favor de los requerimientos de su reino. Prioriza el asunto de la sucesión al trono subvirtiendo así su rol protector como paterfamilias. Salvajemente sentencia a Póstumo al exilio y envía a Imogen a prisión, imaginando un cruento destino para su hija:

¡Tú ente abyecto, vete ya, fuera de mi vista!

Si después de esta orden infieres a la corte

Tu indignidad, has de morir. Fuera,

Veneno eres para mi sangre. (CI, I, i, 124-127)

Criatura desleal,

Tú que mi juventud deberías restaurar

Sumas, en cambio, un año a mi edad. (CI, I, i, 132-134)

[...] fuera con ella y encerradla ya. (CI, I, i, 152-153)

[...] que languidezca (CI, I, i, 157-159)

La falta de pietas de la reina se revela por medio de su hipocresía y su oportunismo ya que sus únicas intenciones son casar a su hijo con Imogen para asegurarse un lugar en la familia real. Al igual que Demetrio y Quirón en Tito Andrónico, Cloten es además de impío, un príncipe vanidoso, violento, vengativo y libidinoso que al ser rechazado por Imogen planea violarla (Miola, 1983, p. 209). Incluso la impietas de Yaquimo se convierte en una amenaza para la familia, ya que recurre a métodos retorcidos para ganar la apuesta que ha hecho a Póstumo acerca de la castidad de Imogen. A las diferentes agresiones hacia la institución familiar, se suma el inminente ataque al estado: Cimbelino se rehúsa a pagar el tributo a Roma, lo que implica "guerra y confusión/ en nombre de César" (CI, III, i, 66). A partir de este comienzo, los ataques al organismo, tanto a la familia como al estado, continúan agravándose. De hecho, hay trece personajes importantes que están involucrados en no menos de veinticinco complicaciones del argumento (Hosley, 1968, p. 24).

En la red de relaciones que se establecen en Cimbelino, se entreteje también el destino del protagonista trágico. Póstumo ironiza el destino del héroe trágico romanizado. La sátira que se transmite por medio de la construcción del destino de Póstumo expone los defectos del código de ética romana por medio de la imitación de los mismos o mediante el contraste. El efecto satírico en el destino del héroe se logra entonces a través de modos de presentación y representación, más que mediante una condena explícita y directa. Póstumo Leonato es el summum de la romanitas y la pietas anglificadas: "Alguien muy querido y elogiado:/ un ejemplo para los jóvenes; para los maduros, / un espejo adonde confrontarse y para los ancianos, / un hijo donde apoyar su vejez" (CI, I, i, 47-50).

$\mathrm{Al}$ igual que otros héroes romanos, Póstumo es heredero de una tradición de honor y excelencia militar (Miola, 1983, p. 210). Hijo de un prestigioso guerrero, es asociado con la imagen del águila romana. Traicionado por su entorno y condenado al exilio, Póstumo se traslada a Roma. Miola (1987, p. 210) observa que su tierna partida difiere ampliamente de las despedidas de Bruto y Porcia, César y Calpurnia, Coriolano y Virgilia, donde los hombres severamente subordinan la emoción privada al deber público. $\mathrm{Ni}$ siquiera Póstumo recuerda aquí a Basanio o Antonio, quienes valientemente afirman su derecho a amar con sus espadas. Esto ocurre justamente porque Póstumo, como héroe romanizado, satiriza el destino de los héroes romanos shakesperianos exponiendo sus debilidades y sus vicios, en este caso por contraste, ya que en su despedida de Imogen el despliegue de genuinas protestas de amor expone el ridículo de las frías separaciones de los dramas romanos anteriores mencionadas por Miola.

Por otra parte, no es casual que el héroe se traslade a Roma, madre devoradora de sus ciudadanos y sus enemigos, ya que es en Roma donde significativamente deviene el comienzo de su autodivisión. Al igual que en el resto de los héroes romanos, la dualidad de Póstumo surge en relación con su afectuosa bondad, por un lado, y su destreza bélica y valor, por el otro. Se involucra en una discusión sobre la fidelidad de las mujeres y apuesta sobre la castidad de Imogen. Así, la integridad que lo ha caracterizado comienza a tambalear. Su honrado amor y su rectitud moral no se condicen con el comentario mediante el que equipara su cariño por Imogen con el amor por lo material, y la sarcástica acotación de Yáquimo acentúa la ambivalencia:

Póstumo: La alabé tanto como la valoraba; lo mismo hago con mi piedra. 
Yáquimo: ¿En cuánto lo valoráis?

Póstumo: Más que todo lo que hay en el mundo.

Yáquimo: $\mathrm{O}$ su dama sin parangón está muerta o la supera el anillo (CI, I, iv, 81-85).

El tratamiento que se da al tema de la castidad en la conversación entre los hombres, equiparándolo con el de la posesión del anillo, convierte a esta virtud en una propiedad. Así como la castidad de Lavinia en Tito Andrónico es propiedad de su padre (Kahn, 1987, p. 160), Póstumo parece erigirse en 'propietario' de la virtud de Imogen, intensificando el rol patriarcal romano. Incluso el apostar sobre la castidad de su amada lo lleva a configurarse como un hombre arrogante, constante como César ("Yáquimo: ¿YY los dioses os la dieron? Póstumo: Y por gracia de ellos, la conservaré", CI, I, iv, 91), soberbio y dominante ("Vuestra Italia no contiene a ningún cortesano tan apuesto que supere la honra de mi amada", CI, I, iv, 100-101). La apuesta sobre la fidelidad de Imogen contribuye además a acentuar la masculinidad, la virilidad y el coraje marcial de Póstumo: "Si no lográis seducirla, y no podéis/ demostrarme lo contrario, tendréis que responderme/ con la espada" (CI, I, iv, 167-170), valores elogiados por el código de virtus romano. De esta manera, el tratamiento de Shakespeare de la tradicional historia de la apuesta expone a Póstumo de manera negativa (Swander, 1964, p. 163).

La autotraición del héroe deviene cuando Póstumo se convence de que Imogen lo ha traicionado y le ha sido infiel. Su reacción frente a la magnitud de la revelación, (“ $i \mathrm{O}$, si estuviera aquí, para arrancarle miembro a miembro!”, CI, II, iv, 148), expone una naturaleza que es contraria a sí mismo. Su afectuosa bondad y su honorabilidad se sustituyen por sus deseos de venganza. Irónicamente, Shakespeare le concede a Póstumo la posibilidad retrospectiva que ha negado a sus otros héroes romanos: un verdadero soliloquio. Bloom (2002, p. 613) lo califica como "demasiado fuerte para Póstumo", y esto se debe a que el soliloquio no tiene cabida en el drama social, ya que impone una matriz que va más allá de la caracterización del héroe en relación con su comunidad. Bloom (2002, p. 613) también pregunta: "¿Por qué atribuye Shakespeare este exabrupto terriblemente antipático a Póstumo?”. Teniendo en cuenta la idiosincrasia del género, puede decirse que Shakespeare lo incluye para satirizar la autotraición del héroe, ya que, en el soliloquio Póstumo, un hombre honorable y afectuoso, exagera sobremanera su papel de vengador. Es grotescamente cómico escuchar al amoroso Póstumo maldecir contra las mujeres:

\footnotetext{
Si encontrara la parte de mujer en mí [...] porque no hay impulso

Tendiente al vicio en el hombre que no provenga,

Como afirmo, de la mujer: si es concupiscencia,

Viene de la mujer; adulación, de ella; engaño, de ella;

Lujuria y malos pensamientos, de ella; venganza, de ella;

Ambición, codicia, orgullos cambiantes, desdén,

Deseos vanos, calumnias, mutabilidad,

Todas las faltas que puede nombrar la tierra, no,/Que

el infierno conoce, son de ella (CI, II, v, 22-28)
}

Exageradamente, su rol de vengador intenta transformarlo en asesino, un papel para el que ciertamente su naturaleza identitaria no está preparada. Movido por sus deseos de venganza (impietas), escribe una carta a su amigo Pisanio, instruyéndolo acerca de cómo matar a Imogen.

La sátira al héroe romano continúa durante el proceso de auto-conquista del protagonista trágico. Póstumo logra la restauración de su virtus mediante un sincero arrepentimiento del daño causado a Imogen y a su comunidad: "Britania, es suficiente que a tu dama haya matado; paz/ no te inferiré más heridas" (CI, v, i, 20-21). Lo grotesco de la escena radica en que Póstumo predica su arrepentimiento vestido de soldado romano, pero a diferencia de tal, decide luchar como un desconocido: "Desconocido, ni odiado, ni compadecido,/ de cara al peligro me entregaré" (CI, V, i, 28-29). Contrariamente a lo que Póstumo decide, el ethos romano en las obras anteriores impulsa al héroe trágico a buscar el reconocimiento, la gloria y la fama por medio del valor militar. Por lo tanto, el ver a Póstumo vestido de romano, con un pañuelo ensangrentado en su mano, humildemente explicando que no busca el reconocimiento personal sino solo morir por su esposa resulta cómico y sarcástico a la vez. Durante la despiadada batalla ("Los amigos matan a los amigos y 
el desorden es tal/ cual si la guerra tuviera los ojos vendados", CI, v, ii, 15-16), Póstumo lucha contra Yáquimo, a quien vence, desarma y deja ir. La mimesis se convierte en una ironía situacional, ya que surge una marcada disparidad entre expectativa y realidad, entre lo que ocurre y lo que se espera. De acuerdo a la ética romana, la realidad de la batalla exige el enfrentamiento y la muerte, pero no contempla la piedad y el perdón.

Sin embargo, Póstumo decide violar el código al actuar discrepantemente. La decisión de Póstumo satiriza la decisión de Antonio de retar a Octavio "a un combate personal" (Shakespeare, Antonio y Cleopatra, IV, i, 3) hasta que uno muera. El héroe britano se reconcilia así con su naturaleza original, recuperando su dignidad, su integridad y su nobleza. Kahn (1987, p. 168) señala que la prueba de la virtus del héroe es su sorprendente perdón a Imogen sin prueba de su inocencia; cuando decide dar su vida en batalla por ella, todavía cree que ella le ha sido infiel con Yaquimo. Póstumo busca morir en manos de los britanos disfrazándose de soldado romano. Al igual que para Antonio y Cleopatra, la muerte para Póstumo implica una especie de redención: "Para mí, la muerte es el rescate” (CI, v, iii, 80). Apresado y esperando su condena, reflexiona nuevamente vestido en ropas romanas, expresando un sincero dolor y ofreciendo su vida por la de su amada:

Por la querida vida de Imogen tomad la mía, Aunque no tan preciosa es una vida; vosotros la acuñásteis.

Entre los hombres, no se pesa cada moneda, Y aunque liviana, se la toma por la imagen;

Tomad la mía, que la vuestra imita. Y así, grandes potencias,

Si aceptárais esta transacción, tomad esta vida

Y cancelad las frías obligaciones. Oh, Imogen,

A ti te hablaré en silencio. (CI, V, iii, 22-29)

La ironía expone una vez más la contradicción del exterior romano de Póstumo con los valores que pregona en su prisión, "una capacidad britana para la humildad y el crecimiento espiritual” (Miola, 1983, p. 228). Este momento de reflexión sobre la vida y la muerte y del triunfo redentor del héroe funciona como un preámbulo para la destrucción o la autodestrucción de Póstumo. Sin embargo, la ironía del argumento establece un giro grotesco una vez más: la aparición de los fantasmas de la familia Leonato que suplican a Júpiter por la vida de Póstumo. La caracterización de la familia es netamente romana. El padre Sicilio está vestido de guerrero y rescata los valores de la fama y la gloria obtenida por el valor militar de su hijo: "Un gran carácter, como en sus antepasados, modeló su materia/ tan bien, que mereció la alabanza del mundo" (CI, v, iii, 39-40). Los hermanos también enfatizan su propio coraje militar: “... luchando por nuestro país caímos con valor y fuimos muertos/ por mantener con honor nuestra lealtad y el derecho de Tenacio" (CI, v, iii, 53-54). La madre invoca a Lucina, diosa romana de los nacimientos, para rememorar el parto doloroso de Póstumo, "un poderoso recordatorio del fuerte principio de control patriarcal" (Kahn, 1987, p. 168) que domina la escena. La aparición de los Leonato, a pesar de haber sido considerada como un aspecto típico del romance (Piña, 2007, p. 17), es netamente funcional al género histórico romano.

En primer lugar, la escena adquiere la connotación irónica característica del género, ya que nuevamente se contrapone el ethos romano, militar, valeroso y patriarcal, con los valores de la súplica y el perdón. En segundo lugar, contribuye a destacar los vínculos familiares y las constantes apelaciones a la genealogía que se dramatizan en el género. Y en tercer lugar, la escena es literalmente grotesca, al asemejarse a las imágenes de los grottoes, que combinaban imágenes romanas humanas con figuras sobrenaturales y animales. Los Leonato, una familia britona y romanizada, aparecen junto al dios Júpiter montado en un águila. Es una representación grotesca visual y conceptualmente, ya que a pesar de haber ofendido a Júpiter y de que el águila sagrada bajase como para tomarlos en sus garras, los Leonato son confortados con la seguridad de que Póstumo “... será el señor de la dama Imogen, y más disfrutará/ su felicidad a causa de su aflicción actual" (CI, v, iii, 79-80). Es grotescamente cómico ver que Júpiter, la principal deidad del panteón romano, montado en un águila, tótem de la ideología romana, intercede a 
favor de los britanos. Si bien Bloom (2001, p. 628) difiere en la interpretación de esta escena, coincide en evaluarla como "bufonesca", "absurda" y una "parodia de una parodia".

En las obras romanas anteriores a Cimbelino el suicidio se dramatizó de acuerdo a la visión ética y estoica romana, como el camino a la recuperación de la dignidad del individuo, ya que la forma de morir es la medida del valor final de la vida. Sin embargo, la connotación del suicidio en el género es irónica, ya que después de que el héroe muere la síntesis que deviene es bastante cuestionable. En Cimbelino, la ironía se intensifica a tal punto que el héroe no se suicida ni es asesinado, y la síntesis que se logra es demasiado absurda. Las palabras del carcelero ironizan, en una escena de tinte cómico, el significado romano del suicidio:

Vuestra muerte tiene ojos en la cabeza, entones; no la He visto pintada así. O bien la orienta alguien que dice Que sabe o cree por sí mismo algo que estoy seguro Propio riesgo. $\mathrm{Y}$ aunque os apresuráis al final de vuestro

Viaje, creo que nunca volveréis para contarlo. (CI, v, iii, 150-156)

El carcelero desmorona la certeza de la gloria que se obtiene al morir y la contrapone con la duda que la muerte representa. Las últimas palabras del género histórico romano acerca del suicidio y la muerte, Shakespeare las concede a este carcelero:

Salvo que un hombre se despose con la horca y tenga Patibulios, nunca vi a uno tan ansioso. Sin embargo, Por mi conciencia, los hay peores y desean vivir, por Más que sea un romano, y hay otros de ellos que Mueren contra su voluntad. Sería mi caso, si fuera Romano. Ojalá todos opináramos lo mismo y opináramos

Bien, ¡sería la ruina de los carceleros y las horcas! Hablo contra mi propio beneficio actual, más mi Deseo habla bien de mí. (CI, v, iv, 170-178)

La comicidad del personaje acentúa la ironía, y desde su humilde perspectiva la vida es mejor que la muerte, aún para los romanos (Miola, 1983, p. 231). En lugar de morir, Póstumo reafirma los valores

del perdón y la compasión, que surgen como irónico contraste a la agresión y la violencia romana, y destaca la importancia de la individuación para el bien social: "No os arrodilles ante mí./ El poder que tengo sobre vos reside en salvaros, / el rencor hacia vos, en perdonaros. Vivid/ y tratad mejor a las personas" (CI, v, v, 418-421).

A pesar de haber sido moldeado por el ethos romano, el héroe en Cimbelino marca una diferencia. Póstumo anglifica los valores romanos mediante el mismo proceso que rige el destino del héroe trágico en el resto del corpus. Este proceso implica la incorporación a su romanitas del perdón, la compasión y la autorrealización por medio de la lucha por el amor y por el bien social (pietas). De esta manera, dos de los valores que Shakespeare explora en las otras obras histórico romanas, pietas y romanitas, adquieren identidad britona en el contexto de Cimbelino. Esta anglificación, que supera las virtudes romanas originales, implica la misma ironía que transmite el resto de las obras romanas: Roma, a pesar de su esplendor histórico, no es un modelo a seguir. Póstumo verbaliza esta ironía, cuando reporta las palabras de Belario al dirigirse a sus compañeros britanos en la batalla contra el imperio de Augusto César: "Deteneos, o seremos como los romanos/ y os daremos la muerte de las bestias que huyen bestialmente" (CI, v, iii, 25-27). De acuerdo a Del Sapio Garbero (2016, p. 15), Roma aparece como una presencia formativa pero que es cuestionada, y la obra caracteriza la relación entre Inglaterra y la Antigua Roma como un proceso de construcción bidireccional combativo, que eventualmente invierte el modelo jerárquico de un centro cultural hegemónico y una periferia subyugada.

Las veinticinco complicaciones que se entretejen en el argumento de Cimbelino se resuelven a favor de la restauración de la armonía y la salud del cuerpo cívico. Las familias se reúnen, Póstumo se rencuentra con su amada Imogen y Cimbelino perdona a todos los cautivos romanos. Sin embargo, la síntesis final que deviene luego de la reconciliación es tan irónica como en el resto del corpus romano shakesperiano. "Después de derrotar sanguinariamente al Imperio romano, en una guerra provocada por su negativa 
a seguir pagando tributo, Cimbelino declara de repente ique él pagará tributo de todas formas!" (Bloom, 2001, p. 632). El gesto es tan caricaturesco como el hecho de que Lucio en Tito Andrónico haya recurrido a los godos para restablecer la paz de Roma, tan irónico como la muerte de Bruto en Julio César que deja a Roma en manos de dos triunviros tiránicos, y tan grotesco como la restitución de la paz en Coriolano por medio del asesinato de Cayo Marcio en manos de la plebe volsca. Del Sapio Garbero (2016, p. 16) resalta otra ironía del cierre de la obra al señalar que es finalmente el anfitrión romano, el invasor autoritario, quien es recibido y alojado como una especie de padre asesinado en un linaje histórico distante.

El deseo final del pueblo britón implica el logro de la síntesis sociopolítica en diferentes niveles ascendentes: la familia, el hogar, la ciudad, la nación y el mundo: "Que la enseña/ romana y la britana ondeen amistosamente juntas" (CI, v, v, 480-481). Cimbelino no habla acerca de la sucesión de imperios, sino de otra forma de logro social y político, que es cuando se remueve el vasallaje, y la unión es un contrato al que se accede libremente (Edwards, en Lee, 2007, p. 413). Por medio de este final se acentúa entonces la importancia de la libertad como instrumento de acción social, cultural y político, que en la obra se logra por medio de principios organicistas renacentistas: el amor como expresión esencial para el éxito de la vida social, la benevolencia, la disposición afectuosa, la caridad y la incondicional y desinteresada entrega de los esfuerzos individuales. De esta forma, Cimbelino supedita estas cualidades a la función del género histórico romano y al mismo tiempo prepara el camino para su exploración intensa en el género del romance.

\section{Conclusiones}

Cimbelino es un drama histórico romano que comparte las mismas características que Tito Andrónico, Julio César, Antonio y Cleopatra y Coriolano. Al igual que sus antecesores genéricos, Cimbelino explora el mundo social y el individuo en relación con ese orden, y enfatiza la necesidad esencial de la armonía orgánica. Al igual que en sus dramas romanos previos, Shakespeare realiza esta exploración no por virtud sino por defecto de los valores que contribuyen a la unidad social. La diferencia radica en que el universo social de Tito Andrónico, Julio César, Antonio y Cleopatra y Coriolano es Roma, mientras que Cimbelino se desarrolla en la Bretaña romanizada y Roma aparece como el Otro. El punto de vista de la mimesis y la diegesis se revierten, ya que son los britanos quienes se miden con relación a Roma y a sí mismos. La fuerte tonalidad farsesca e irónica de Cimbelino permite parodiar los elementos del género, sobre todo el destino del héroe, quien a pesar de haber sido moldeado por el ethos romano lo anglifica en su proceso de autoconquista.

Es interesante en esta discusión señalar la interpretación que ofrece Di Michele (2016) en relación con la anglificación de los valores romanos: ésta se produce como una metamorfosis de la que emerge una nueva nacionalidad que conjuga valores tanto masculinos (Roma) como femeninos (Inglaterra). Dicha conjugación se ve representada en la obra por Imogen (hija de Cimbelino); figura que emerge como una imagen fundamental, capaz de sintetizar lo masculino (a través del recurso del disfraz) y lo femenino, y que posee el mismo poder arquetípico de Volumnia o Lucrece.

La ironía que la obra presenta en relación a los valores romanos y la hipocresía de su práctica, es la misma que subyace en el resto del corpus. Cimbelino reconoce la victoria de Roma como un ícono histórico que sigue influenciando la realidad social y cultural de la Inglaterra del siglo I y de la Italia renacentista, pero al mismo tiempo demuele su imagen como modelo social. Esto se logra al dramatizar la independencia de Bretaña y al ironizar el modelo romano, que en última instancia, aunque híbrido, es superado por el modelo britón.

Durante el proceso de autoconstrucción de la idiosincrasia inglesa premoderna, en el que el gobierno isabelino y jacobino imponen un ideal de orden y control como constructo ideológico, Cimbelino (y en general todo el drama romano shakesperiano) ofrece 
un paradigma alternativo en el que ese ideal aparece como un mito con contradicciones esenciales. Cimbelino, inscripto en el proceso de construcción de la poiesis nacional inglesa del período premoderno, se posiciona como una alternativa discursiva frente a la perspectiva monológica propuesta por Tillyard (1943). Esta obra shakesperiana despliega una concepción que da lugar al conflicto y a una cosmovisión determinada por contradicciones inherentes al choque de dos modelos culturales e históricos, uno britón-nacional y otro extranjero-romano. Por consiguiente, el posicionamiento de la obra frente al contexto de su época, implicaría un cuestionamiento de las ideas centrales subyacentes a la ideología del orden natural impuesto por el régimen isabelino. Siguiendo el razonamiento tillyardiano, al presentarse como modelo de disenso, Cimbelino y su autor, William Shakespeare, se posicionarían en un lugar de cuestionamiento hacia el núcleo erudito que dictaminaba las creencias de la época isabelina.

Cimbelino es la despedida de Shakespeare de sus dramas romanos, y por medio de esta obra el dramaturgo completa la exploración de una visión que es romana pero que fundamentalmente es orgánica y social. Es la pieza perfecta que completa el diálogo entre el dramaturgo y Roma, en el que se establece una dialéctica ironía entre virtus y praxis, que devela al ethos romano como contradictorio y perjudicial para la salud social. De esta manera, considerar a Cimbelino como una obra que "tolera a las inconsistencias y se abstiene del análisis político" en términos de Miola (1983, p. 206) significa vaciar el constructo del género histórico romano de uno de sus pilares y negar que, fundamentalmente, además de actor y dramaturgo "Shakespeare era un pensador" (Kermode, en Green, 2005, p. 11).

A partir del análisis de Cimbelino también es posible develar que las identidades nacionales y culturales se encuentran en constante producción (en términos de Hall, 1990, p. 227), siempre en proceso, nunca acabado y constituyéndose dentro de representaciones culturales como la literatura. Cimbelino gira en torno a la identidad cultural de una actual metrópolis pero que en su génesis se autopercibe como periférica frente al poderío de Roma (la madre devoradora). A partir del presente análisis, desde nuestro posicionamiento como lectores latinoamericanos, podemos percibir una especie de ironía colonial, ya que los procesos y las categorías inherentes a la colonización (centro/ periferia; colonizador/colonizado; dominación/subyugación) que caracterizarán el poderío del Imperio Británico, se revierten en Cimbelino. Dicha obra construye una Inglaterra que se rebela contra el imperialismo romanoy, desde nuestra perspectiva del sur global, sabemos que Inglaterra incorporará el mismo ethos imperial a su propia conquista del mundo.

\section{Referencias}

Alexander, M. (1979). An introduction to Shakespeare and his contemporaries. Londres: Pan Books.

Asquith, C. (2005). Shadowplay. The hidden beliefs and coded politics of William Shakespeare. Nueva York: Public Affairs.

Bazerman, C. (1994). Constructing experience. Illinois: Illinois University Press.

Bergeron, D. (1980). Cymbeline: Shakespeare's Last Roman Play. Shakespeare Quarterly, 31(1), 31-41. https://doi. org/10.2307/2869367

Bloom, H. (2001). Shakespeare. La invención de lo humano. Bogotá: Norma.

De Aguiar e Silva, V. (2005). Teoría de la literatura. España: Gredos.

Bodanella, P. (1987). The eternal city. Roman images in the modern world. Carolina del Norte: The University of North Caroline Press.

Del Sapio Garbero, M. (Ed.) (2016). Identity, otherness and empire in Shakespeare's Rome. Great Britain: TJ International. https://doi.org/10.4324/9781315252766

Di Michele (2016). Shakespeare's writing of Rome on Cymbeline. En M. del Sapio Garbero (Ed.), Identity, otherness and empire in Shakespeare's Rome (pp. 157-174). Great Britain: TJ International.

Evans, B. (1960). Shakespeare's comedies. Oxford: The Clarendon Press.

Fletcher, J. ed. (1968). Cymbeline. usA: A Signet Classic.

Frye, N. (1968). The tragedy of order: Julius Caesar. En L. Dean (Ed.), Twentieth century interpretations of Julius Caesar (pp. 95-102). Londres: Prentice-Hall.

Frye, N. (1968). Cymbeline. From a natural perspective. En Barnet, S. (Ed.), Cymbeline (pp. 237-241). UsA: A Signet Classic. 
Green, A. (2005). Sortilegios de la seducción. Buenos Aires: Paidós Diagonales.

Greenblatt, S. (1988). Representing the English Renaissance. USA: University of California Press.

Halio, J. (1992). The late plays and the fulfillment of Shakespeare's tragic pattern. En M. Hunt (Ed.), Approaches to teaching Shakespeare's The tempest and other late romances (pp. 31-38). Nueva York: The Modern Language Association of America.

Hall, S. (1990). Cultural identity and diaspora. En P. Williams y L. Chrisman, (Eds.), Colonial discourse and post-colonial theory: A reader (pp. 227-237). Londres: Harvester Wheatseaf.

Halliday, F. (1985). Shakespeare. Londres: Thames \& Hudson.

Hainze, E. (2016). Legal hybridity in Shakespeare: Revisiting the post-colonial in The Tempest and Cymbeline. Queen Mary School of Law Legal Studies Research Paper N. 215/2016. Disponible en SSRN: https://ssrn.com/ abstract $=2715699$

Hibbert, C. (2005). Rome. The biography of a city. Londres: Penguin Books.

Hosley, R. (ed.) (1968). Cymbeline. Canadá: Signet Classic.

Ingledew, J. (1971). Antony and Cleopatra. Singapur: Longman.

Johnson, S. (1765). Prefacio a Shakespeare. Disponible en https://es.scribd.com/document/258850022/ Prefacio-a-Shakespeare-Samuel-Johnson

Kahn, C. (1987). Roman Shakespeare. Warriors, wounds and women. Londres: Routledge.

Kuhn, T. (1990). La estructura de las revoluciones cientificas. Buenos Aires: Fondo de Cultura Económica.

Lee, K. (2007). Shakespeare's England, Shakespeare's Rome: National anxiety and imperial nostalgia. Medieval and Early Modern English Studies, 15(2), 395-418. https://doi.org/10.17054/memes.2007.15.2.395

Lewis, C. T. y Short, C. (1958[1879]). A new Latin dictionary. NuevaYork: Oxford. Recuperado de https://archive. org/details/LewisAndShortANewLatinDictionary/ page/n1387

Miola, R. (1983). Shakespeare's Rome. Londres: Cambridge University Press. https://doi.org/10.1017/ CBO9780511518966
Monney, M. (1992). Defining the dramaturgy of the late romances. En M. Hunt (Ed.), Approaches to teaching Shakespeare's The tempest and other late romances (pp. 57-63). Nueva York: The Modern Language Association of America.

Pieters, J. (2001). Moments of negotiation. Ámsterdam: Amsterdam University Press.

Piña, C. (ed). (2007). Cimbelino. Buenos Aires: Losada.

Puchmüller, A. (2007). Los dramas histórico-romanos de Shakespeare: Lugar, competencia e identidad (pp. 19-24). Actas del IV Simposio Nacional Ecos de la Literatura Renacentista Inglesa, Facultad de Filosofía y Letras. Universidad Nacional de Cuyo. Mendoza.

Reale, G. y Antiseri, D. (1999). Historia del pensamiento filosófico y cientifico. Tomo II. Barcelona: Herder.

Ronan, C. (1995). Antike Roman. Power symbology and the Roman play in early modern England, 1585-1635. USA: The University of Georgia Press.

Shakespeare, W. (2000 [1623]). Cimbelino (traducido por César Aira). Argentina: Grupo Editorial Norma.

Shakespeare, W. (2001). Antonio y Cleopatra (editado por M. Dionis-Bayer). Col. Letras Universales. Madrid: Cátedra.

Spenser, T. (1957). Shakespeare and the Elizabethan Romans. Londres: Cambridge University Press. https://doi. org/10.1017/CCOL0521064236.003

Steible, M. (2004). Coriolanus. Connecticut: Greenwood Press.

Swander, H. (1964). Cymbeline and the blameless hero. ELH, 31(3), 259-270. https://doi.org/10.1017/ CCOL0521064236.003

Thomas, V. (1991). Shakespeare's Roman worlds. Londres: Routledge.

Tillyard, E. (1943). The Elizabethan world picture. Londres: Random House.

Todorov, T. (1976). The origin of genres. USA: New Literary History. https://doi.org/10.2307/468619

Waller, G. (1992). The late plays as family romance. En M. Hunt (Ed.), Approaches to teaching Shakespeare's The tempest and other late romances (pp. 57-64). Nueva York: The Modern Language Association of America.

How to reference this article: Puchmüller, Andrea Bibiana. (2019). Identidad inglesa premoderna y Otredad romana en Cimbelino de Shakespeare: consideraciones desde el género. Íkala, Revista de Lenguaje y Cultura, 25(1), 251-267, http://doi.org/10.17533/udea.ikala.v25n01a12 